\title{
Comparing Dynamic Pies: A Strategy for Modeling Compositional Variables in Time and Space
}

Article · August 2017

DOI: $10.1017 /$ psrm.2017.39

CITATIONS

0

4 authors, including:

Andrew Q. Philips

University of Colorado Boulder

11 PUBLICATIONS 18 CITATIONS

SEE PROFILE
READS

23

Some of the authors of this publication are also working on these related projects:

Project ARDL project View project

All content following this page was uploaded by Andrew Q. Philips on 15 August 2017. 


\title{
Comparing Dynamic Pies: A Strategy for Modeling Compositional Variables in Time and Space*
}

\author{
Christine S. Lipsmeyer ${ }^{\dagger} \quad$ Andrew Q. Philips ${ }^{\ddagger} \quad$ Amanda Rutherford $^{\S}$ \\ Guy D. Whitten ${ }^{\text {II }}$
}

August 15, 2017

Forthcoming at Political Science Research and Methods

\begin{abstract}
Across a broad range of fields in political science, there are many theoretically interesting dependent variables that can be characterized as compositions. We build on recent work that has developed strategies for modeling variation in such variables over time by extending them to models of time series cross sectional data. We discuss how researchers can incorporate the influence of contextual variables and spatial relationship into such models. To demonstrate the utility of our proposed strategies, we present a methodological illustration using an analysis of budgetary expenditures in the U.S. states.
\end{abstract}

${ }^{*}$ Earlier versions of this paper were presented at the 2015 conference on "Innovations in Comparative Political Methodology" at Texas A\&M University, the 2015 MPSA meetings, and at the University of São Paulo. The authors thank these audiences for their helpful comments.

${ }^{\dagger}$ Associate Professor, Department of Political Science, Texas A\&M University, 2010 Allen Building, 4348 TAMU, College Station, TX 77843-4348 (lipsmeyer@pols.tamu.edu).

¥Assistant Professor, Department of Political Science, University of Colorado at Boulder, UCB 333, Boulder, CO 80309-0333 (andrew.philips@ colorado.edu).

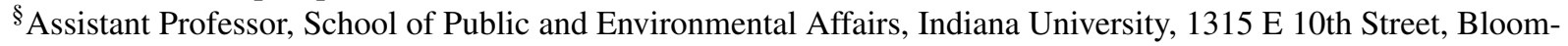
ington, IN 47405-1106 (aruther@indiana.edu).

IProfessor, Department of Political Science, Texas A\&M University, 2010 Allen Building, 4348 TAMU, College Station, TX 77843-4348 (g-whitten@ pols.tamu.edu). Corresponding author. 


\section{Introduction}

Across a broad range of fields in political science, there are many theoretically interesting dependent variables that can be characterized as compositions. The vote shares of competing political parties and the shares of budgets allocated to different spending categories are two of the most prominent examples. Researchers have long recognized the complications that compositional data pose and have implemented strategies developed by statisticians and researchers in other fields to test their hypotheses about such variables with cross sectional data.

More recently, researchers have adapted these modeling strategies to dynamic contexts where they have measured values of a compositional dependent variable over multiple time points for the same spatial unit. These approaches represent substantial improvements over previous strategies for dealing with such dependent variables, which either oversimplified the compositional nature of these data, or ignored the possibility that dynamic relationships shaped them. However, even fully-dynamic compositional models are limited, because they do not allow for the analysis of theoretically interesting variation across both time and spatial units. This means that researchers cannot get leverage on the effects of variables that do not vary much or at all within a single time series. As a multitude of recent papers have demonstrated, there is abundant evidence that what is happening in one spatial unit often affects what happens in other spatial units, especially those that are closely linked together through geography or other factors (Beck, Gleditsch and Beardsley 2006; Franzese and Hays 2007; Neumayer and Plümper 2012; Darmofal 2015).

In this paper, we build on previous work in two ways. First, we develop a strategy for adapting dynamic compositional models to time series cross sectional contexts in which we can model the effects of contextual and spatial relationships across units. We do this by extending the modeling strategy developed by Philips, Rutherford and Whitten (2016a). Second, since modeling strategies for compositional dependent variables produce non-linear estimated relationships and most of them produce copious statistical output, graphical techniques for interpretation have been quite popular. 
Therefore, we also present a series of new graphical strategies to help with the interpretation of the results from models of compositional variables over time and space.

In the next section, we provide a brief discussion of the analysis of compositional dependent variables over time and discuss a series of extensions of these models to data that vary across both time and space. We then provide a methodological illustration of these extensions using budgeting data from the U.S. states. Finally, we include a discussion of our contributions and some possible future directions.

\section{Modeling Compositional Dependent Variables Over Time}

There has been a growing body of work on dynamic compositional dependent variables in political science in recent years. Examining government responses to fiscal austerity in 21 OECD countries, Breunig and Busemeyer (2012) model relative changes between budgetary categories. As they state, explicitly modeling trade-offs between categories moves closer to the "empirical reality of governmental decision-making, where policy-makers are constantly faced with decisions on how to allocate scarce public resources across budget categories" (p. 923). Such a modeling strategy was substantially extended by Philips, Rutherford and Whitten (2015, 2016a), who advocate for the use of graphical depictions of counterfactual "shocks" to variables of substantive interest.

Since compositional data have many unique qualities, it is worth describing them in some detail. Consider a compositional dependent variable, $\mathbf{Y}$, that consists of $C$ components. ${ }^{1}$ Individual observations of each component at each point in time, $y_{c t}$, have the same four defining characteristics. $^{2}$ First, each component of the composition has a value between zero and one $\left(0<y_{c t}<1\right)$.

\footnotetext{
${ }^{1}$ Although Philips, Rutherford and Whitten (2016a) refer to the components of the compositional variable as $J$, we denote them as $C$ in order to avoid confusion when adding spatial effects below.

${ }^{2}$ In later sections, we extend the basic logic of what we are doing to a pooled time series setting, where each value in the vector of the dependent variable is triple indexed $y_{i c t}$ to reflect that it is the value from spatial unit " $i$ " of part "c" observed at time "t."
} 
Second, the components sum to one at each point in time $\left(\sum_{c=1}^{C} y_{c t}=1 \quad \forall t\right) .{ }^{3}$ Third, any change in a single component is bounded by -1 and $1\left(-1<\Delta y_{c t}<1\right)$. Fourth, all changes among component parts at any single point in time must sum to zero $\left(\sum_{c=1}^{C} \Delta y_{c t}=0\right)$.

When $C=2$, models with $y_{c t}$ can be estimated with an OLS regression model. ${ }^{4}$ When $C>2$, matters become considerably more complicated. As Aitchison (1982, 1983, 1986) demonstrated, any modeling approach that assumes independence across the columns of $\mathbf{Y}$ will be problematic. Following Aitchison, for a compositional dependent variable, $y_{c t}$, with $C$ components and a chosen reference category, $c=1$, we can calculate $C-1 \operatorname{logged}$ ratios, which we label $s_{c t}$, such that

$$
s_{c t}=\ln \left(\frac{y_{c t}}{y_{1 t}}\right) \quad \forall c \neq 1 .
$$

We then can estimate the effects of independent variables in each of the $\mathrm{C}-1$ equations, because one of the categories, $y_{1 t}$, becomes the "baseline" for all the log-ratios; the choice of baseline category is arbitrary.

The modeling strategy proposed by Philips, Rutherford and Whitten (2016a) to test theoretical claims about compositional dependent variables with more than two categories in models for a single spatial unit over time is given as

$$
\Delta s_{c t}=\beta_{0 c}-\alpha_{c} s_{c, t-1}+\boldsymbol{\beta}_{L c} \mathbf{x}_{t-1}+\boldsymbol{\beta}_{S c} \Delta \mathbf{x}_{t}+\varepsilon_{c t}
$$

- where $\Delta s_{c t}$ is the change in the logged ratio of dependent variable category "c" for $c>1$ relative to baseline category $c=1$ from time " $t-1$ " to time " $t$,"

- $\mathbf{x}_{t}$ is a vector of independent variable values at time " $\mathrm{t}$,"

\footnotetext{
${ }^{3}$ We can, of course, use some positive constant value other than one; for instance, the parts could sum to 100 percent.

${ }^{4}$ Of course, OLS may still not be ideal due to the boundedness of the series (Katz and King 1999).

${ }^{5}$ As noted above, the choice of which category to set as the baseline category ( $c=1$ in this case) is arbitrary as long as $0<V_{c t}<1$ (and does not alter the resulting statistical inferences).
} 
- $-\alpha_{c}$ are adjustment parameters that measure the long-run error correction processes,

- $\boldsymbol{\beta}_{S c}$ is a vector of short-run effects,

- $\boldsymbol{\beta}_{L c}$ is a vector of parameters that can be combined with $-\alpha_{c}$ to calculate estimated long-run effects of changes in each independent variable, ${ }^{6}$

- and $\varepsilon_{c t}$ is a stochastic disturbance term that may be correlated across the $C-1$ equations.

As is clear from Equation 2, Philips, Rutherford, and Whitten's (2016) recommendation is for a system of error correction equations, and the advantage of this approach is that it estimates both the short- and long-run effects of changes in any of the independent variables. Because of the extensive parameterization from these models, these authors recommend the use of graphical simulations for the interpretation of the estimated relationships; we build on their work along these lines below.

\section{Extending Dynamic Compositional Models Across Space}

We can gain leverage on a wide range of concepts of theoretical interest by extending the dynamic compositional models proposed by Philips, Rutherford and Whitten (2016a) to time series cross sectional data. In this section, we provide an overview of the details of how we can adapt these modeling strategies from models of single spatial units over time. As a first step, we adjust the system of equations represented in Equation 2 by adding an " $i$ " subscript for different spatial units such that our equation becomes

$$
\Delta s_{i c t}=\beta_{0 c}-\alpha_{c} s_{i c, t-1}+\boldsymbol{\beta}_{L c} \mathbf{x}_{i, t-1}+\boldsymbol{\beta}_{S c} \Delta \mathbf{x}_{i t}+\varepsilon_{i c t} .
$$

\footnotetext{
${ }^{6}$ We write the error correction process as $-\alpha_{c}\left[s_{c, t-1}-\kappa_{c} x_{t-1}\right]$ where $\beta_{L c}=\alpha_{c} \kappa_{c}$. We calculate the long run effects as $L R_{c}=\frac{\alpha_{c} \kappa_{c}}{-\alpha_{c}}$.
} 
Models of time series cross sectional data have become prevalent in nearly all subfields of political science. Two of the biggest attractions of this broad class of models are that they allow researchers to gain leverage on the impact of contextual independent variables that do not vary much (or at all) within single spatial units over time (e.g., Plümper and Troeger 2007; Clark and Linzer 2015), and that they allow researchers to model the impact of spatial processes in which aspects of what is happening in unit "j" affect the dependent variable in unit "i" (e.g., Beck, Gleditsch and Beardsley 2006; Franzese and Hays 2007). Our main goal is to show how researchers can accomplish both of these tasks when the dependent variable is a composition. For ease of exposition, we first discuss the incorporation of spatial factors and then proceed to consider the inclusion of interactive contextual factors.

Recent literature on spatial statistical models has advocated the spatial-X model as a good starting point for testing theories about spatial effects (Halleck Vega and Elhorst 2015). Although we also consider spatially-lagged (i.e., spatial-Y) models below, we find this setup particularly attractive due its flexibility in terms of model specification and the ease with which researchers can estimate it. We can incorporate theoretically-interesting spatial effects through the inclusion of a set of $\boldsymbol{\theta W Z}$ terms

$$
\Delta s_{i c t}=\beta_{0 c}-\alpha_{c} s_{i c, t-1}+\boldsymbol{\beta}_{L c} \mathbf{x}_{i, t-1}+\boldsymbol{\beta}_{S c} \Delta \mathbf{x}_{i t}+\boldsymbol{\theta}_{L c} \mathbf{W} \mathbf{Z}_{t-1}+\boldsymbol{\theta} \mathbf{W} \Delta_{S c} \mathbf{Z}_{t}+\varepsilon_{i c t}
$$

where $\boldsymbol{\theta}$ is a vector of spatial parameters to be estimated, $\mathbf{W}$ is the theoretically specified weights matrix connecting our spatial units, and $\mathbf{Z}$ is a matrix of variables with values for other spatial units $(j \neq i)$ that are expected to work through $\boldsymbol{\theta}$ and $\mathbf{W}$ to affect $s_{i c t}$. Presently, we are interested in testing theories about two types of spatial effects: spillover effects and spatial diffusion/contagion effects. For spillover effects, we populate our $\mathbf{Z}$ matrix with contemporaneous or lagged values of selected variables from $\mathbf{x}$, and we provide an example of this type of effect below. Readers familiar with spatial statistical models will recognize this model, regardless of the variables included in $\mathbf{Z}$, 
as a spatial-X (SLX) model. ${ }^{7}$ In order to estimate spatial diffusion/contagion effects, we use $s_{j c t}$ values to estimate a spatial autoregressive model, known as a "SAR" model. As recent work has demonstrated, for both types of models, the specification of $\mathbf{W}$ must be done based on theoretical expectations about how changes in surrounding spatial units affect each other (Neumayer and Plümper 2012).

As outlined above, another attractive reason for extending these models to the pooled time series setting is that it gives us the ability to test for the impact of contextual variables such as institutions, government partisanship, and other variables that do not usually vary much within a single time series. If we theorize that these variables work in an additive fashion, they can appear in our models as just another element in $\mathbf{x}$. However, we often expect these variables to work through the other independent variables to affect the phenomena being modeled. Following the example of Philips, Rutherford and Whitten (2015), we can model the effects of such variables with a dichotomous indicator, $d_{i t}$, that we interact with the theoretically-relevant right-hand side variables in our models. ${ }^{8}$ To apply this to a setting that also includes the spatial effects (as depicted in Equation 4), we first collect the lagged dependent variable $s_{i c, t-1}$ and the vector of parameters for the lagged independent variables and express them as a function of the adjustment parameter $\alpha_{c}$

$$
\Delta s_{i c t}=\beta_{0 c}-\alpha_{c}\left(s_{i c, t-1}+\boldsymbol{\kappa}_{L c} \mathbf{x}_{i t-1}+\boldsymbol{\omega}_{L c} \mathbf{W} \mathbf{Z}_{t-1}\right)+\boldsymbol{\beta}_{S c} \Delta \mathbf{x}_{i t}+\boldsymbol{\theta} \mathbf{W} \Delta_{S c} \mathbf{Z}_{t}+\varepsilon_{i c t}
$$

\footnotetext{
${ }^{7}$ Unlike much of the literature on SLX models, we use $\mathbf{Z}$ instead of $\mathbf{X}$ to allow for the possibility that the independent variables in $\mathbf{Z}$ might be different from those in $\mathbf{x}$.

${ }^{8}$ In the present notation and applied example, for ease of presentation, we interact $d_{i t}$ with all of the independent variables in our model.
} 
where $\boldsymbol{\beta}_{L c}=\frac{-\boldsymbol{\kappa}_{L c}}{\alpha_{c}}$ and $\boldsymbol{\theta}_{L c}=\frac{-\boldsymbol{\omega}_{L c}}{\alpha_{c}}$. We then add the term $d_{i t} \phi_{c}$ to the adjustment parameter and $d_{i t} \zeta_{c}$ to the short-run parameters to change our system of equations to

$\Delta s_{i c t}=\beta_{0 c}-\alpha_{c}\left(1+d_{i t} \phi_{c}\right)\left(s_{i c, t-1}+\mathbf{x}_{i, t-1} \boldsymbol{\kappa}_{L c}+\boldsymbol{\omega}_{L c} \mathbf{W} \mathbf{Z}_{t-1}\right)+\left(1+d_{i t} \zeta_{c}\right)\left(\Delta \mathbf{x}_{i t} \boldsymbol{\beta}_{S c}+\boldsymbol{\theta} \mathbf{W} \Delta_{S c} \mathbf{Z}_{t}\right)+\boldsymbol{\Sigma}_{i c t}$.

This specification allows both the short- and long-run adjustments to vary depending on the value of $d_{i t}$. When $d_{i t}=0$, Equation 6 reverts back to Equation 5 .

In the next section, we show an example of a model estimated with both spatial effects and partisan effects, which we measure with a $d_{i t}$ term. To help interpret these effects, we develop figures that depict the substantive changes that are a consequence of simulated changes to the values of an independent variable.

\section{Methodological Illustration-Budgeting in US States}

As a methodological illustration of the modeling strategies discussed above, we conducted an analysis of the role of partisanship in shaping the annual budgets of the 48 contiguous U.S. states. We collected data for this example from the U.S. Census Annual Survey of Government Finance from 1977 to 2008. This survey provides information on major revenue and expenditure categories for each state in current dollars for a fiscal year (for example, 1992 would reflect expenditures for the fiscal year spanning July 1, 1991 and June 30, 1992). Data are compiled from state government budgets, audits, and additional financial reports, which the Census Bureau compiled and reassigned to classification categories to make them directly comparable.

The dependent variable consists of five components, expressed as proportions, that define direct expenditures by function in each state across time: education, social services (i.e., public welfare, hospitals, and veterans services), public services (transportation, public safety, and housing), labor 
market policy, and a collection of smaller categories which we lumped together as "Other." ${ }^{9}$ Since these are compositional data, all five components sum to 1 in each year for each state.

For our independent variables in this example, we relied on collections of data from Klarner $(2013 a, b)$ and the Bureau of Economic Analysis. We present results from a relatively parsimonious model in which the independent variables are average real state personal income, the rate of unemployment in the state, the rate of unemployment in other states, and the partisanship of the state governor. In this model, the unemployment rate in other states is our spatial variable, referenced as $\mathbf{Z}$ in equations 4 through 6. Our expectation is that unemployment in other states is seen as a harbinger of tough economic times and thus leads politicians to adjust their budgets in expectation of future changes. In thinking about how unemployment in other states is likely to affect budgeting in each state, we expect this to be a function of two factors: geographic proximity and economic size relative to all other states. We thus constructed a weights matrix, $\mathbf{W}$, that is the product of two different weights matrices:

$$
\mathbf{W}=\left(\mathbf{W}_{1 / \text { dist }} \cdot \mathbf{W}_{\text {row-std.Econ }}\right)
$$

where $\mathbf{W}_{\text {row-std.Econ }}$ is a row-standardized weights matrix of each state's contribution to national personal income, which we pre-multiply by $\mathbf{W}_{1 / \text { dist }}$, that is an un-standardized inverse distance matrix (such that states that are further away get lower weights). ${ }^{10}$ This specification reflects our theoretical expectations; for example, even though Oregon is geographically more proximate to the state of Washington than California, California's dominant economic influence in the region likely means that changes in economic conditions in that state are still substantial in Washington. Thus, this weights matrix specification takes into account both distance and economic influence.

\footnotetext{
${ }^{9}$ This category includes interest paid on general debt, as well as spending on the environment, liquor stores, utilities, and general expenditures not elsewhere classified. Across our sample, the "Other" category averages less than 10 percent of state budgets. In future work, we intend to explore further breakdowns on budgetary categories, but in the present application, we limit our analysis to the four largest expenditure categories plus all others in order to make the presentation of our results more tractable.

${ }^{10}$ We row-standardize personal income to reflect the fiscal size of the state relative to all other states.
} 
In this example, we model gubernatorial partisanship as our contextual factor, referenced as $d_{i t}$ in Equation 6. Here, $d_{i t}=1$ if the current governor is a Democrat and zero otherwise. ${ }^{11}$ We are thus allowing the effects of all of our other independent variables on budgeting to differ depending on the partisanship of the state's governor.

Results using a model specified according to Equation 3 produce a heavy parameterization; the five dependent variable categories create four compositional trade-offs with 16 parameters (plus a constant) in each equation. ${ }^{12}$ Instead of presenting a table of parameter estimates, we follow the current convention of presenting the results from dynamic simulations (Philips, Rutherford and Whitten 2016a,b; Williams and Whitten 2011, 2012). ${ }^{13}$ More specifically, we follow the lead of Philips, Rutherford and Whitten (2016a) and present figures depicting "change from baseline" simulation scenarios. To obtain the quantities for these figures, we first estimate each of the $C-1$ equations in a seemingly unrelated regression framework using the Clarify program developed by Tomz, Wittenberg and King (2003). Estimating compositional variables in a seemingly unrelated regression is ideal due to the potential for contemporaneous correlation of errors, as well as the fact that the components must sum to one (Tomz, Tucker and Wittenberg 2002; Jackson 2002; Mikhailov, Niemi and Weimer 2002). ${ }^{14}$ Next, after creating posterior densities of our parameter estimates through 1000 sets of simulations, we set the lagged dependent variable of each category to its sample mean, $\bar{Y}_{c}$. The differenced independent variables are set to zero, while the lagged independent variables are set to their sample means. We then take the expected value of each of our dependent variables at time $t$. This becomes the new value of the lagged dependent variable at time $t+1$. This process is repeated until period 4 , when we change one of the differenced independent

\footnotetext{
${ }^{11}$ Note that the zero category includes both Republican and Independent governors. Independent governors comprised only 18 state-years in our dataset, representing just over one percent of the data; therefore, we refer to the category when $d_{i t}=0$ as "Republican."

${ }^{12}$ We end up with 16 parameters: each of the three independent variables appears in both lagged levels and firstdifferences, each lagged level and first-difference multiplied by the interaction term for the governor's partisanship, the dummy variable for partisanship (its lag and first-difference), as well as the lagged dependent variable and its interaction with partisanship.

${ }^{13}$ The table of results is available in the Appendix.

${ }^{14}$ Of course, since these components are transformed into logged ratios before estimation in a SUR, these $C-1$ compositions no longer sum to one. Still, we expect that an overestimation in one composition is likely to be associated with an underestimation in another.
} 
variables of interest by one standard deviation. In period 5, the differenced independent variable becomes zero again, and the "shock" gets added to the mean of the respective lagged independent variable. After 20 iterations, we save the results and un-transform the $\hat{s}_{i j t}$ values to yield the expected proportion of each category, along with 95 percent confidence intervals calculated using the percentile method. The formula for the un-transformation is

$$
\hat{y}_{i j t}=\frac{e^{\hat{s}_{i j t}}}{1+\sum_{c=2}^{C} e^{\hat{s}_{i j t}}} \forall c>1
$$

and

$$
\hat{y}_{i j t}=\frac{1}{1+\sum_{c=2}^{C} e^{\hat{s}_{i j t}}}
$$

for the baseline category. The resulting output is then graphed over time around the expected value of the individual dependent variable categories in each of the simulated time periods with surrounding confidence intervals. ${ }^{15}$

By treating every compositional equation as part of a broader system (i.e., the entire budget), we are able to gain a rich set of big picture inferences. In addition, we are able to overcome one of the major difficulties in graphically presenting results from analyses of compositional dependent variables using traditional simplex and/or ternary plots. These difficulties are summarized by Wang et al. (2007, p. 459-468) as, "A popular way to represent the data is through a p-dimension ternary diagram (although there is no satisfactory visual representation when $p>4$ ) with each component $x_{j}$ corresponding to the perpendicular point from the representative point to the triangular face opposite the vertex j." As we show below, there are multiple graphical approaches to help with the interpretation of the substantive results from our models, and they do so effectively with more than four categories of the dependent variable.

Figure 1 shows an example of a change from baseline simulation from a one standard deviation decrease in personal income at time $t=4$. The plot on the left shows the starting composition and

\footnotetext{
${ }^{15}$ This use of expected values and their confidence intervals is in line with the current convention of interpreting estimated effects without accounting for total model error, as would be the case if we used predicted values instead of expected values.
} 
budgetary response to such a shock under a Democratic governor, while the plot on the right shows the response to the same shock under a Republican governor. Although 95 percent confidence intervals are shown for all time points in the simulation, they are often not much larger than the icons depicting the point estimates with the exception of the shock period at $t=4$.
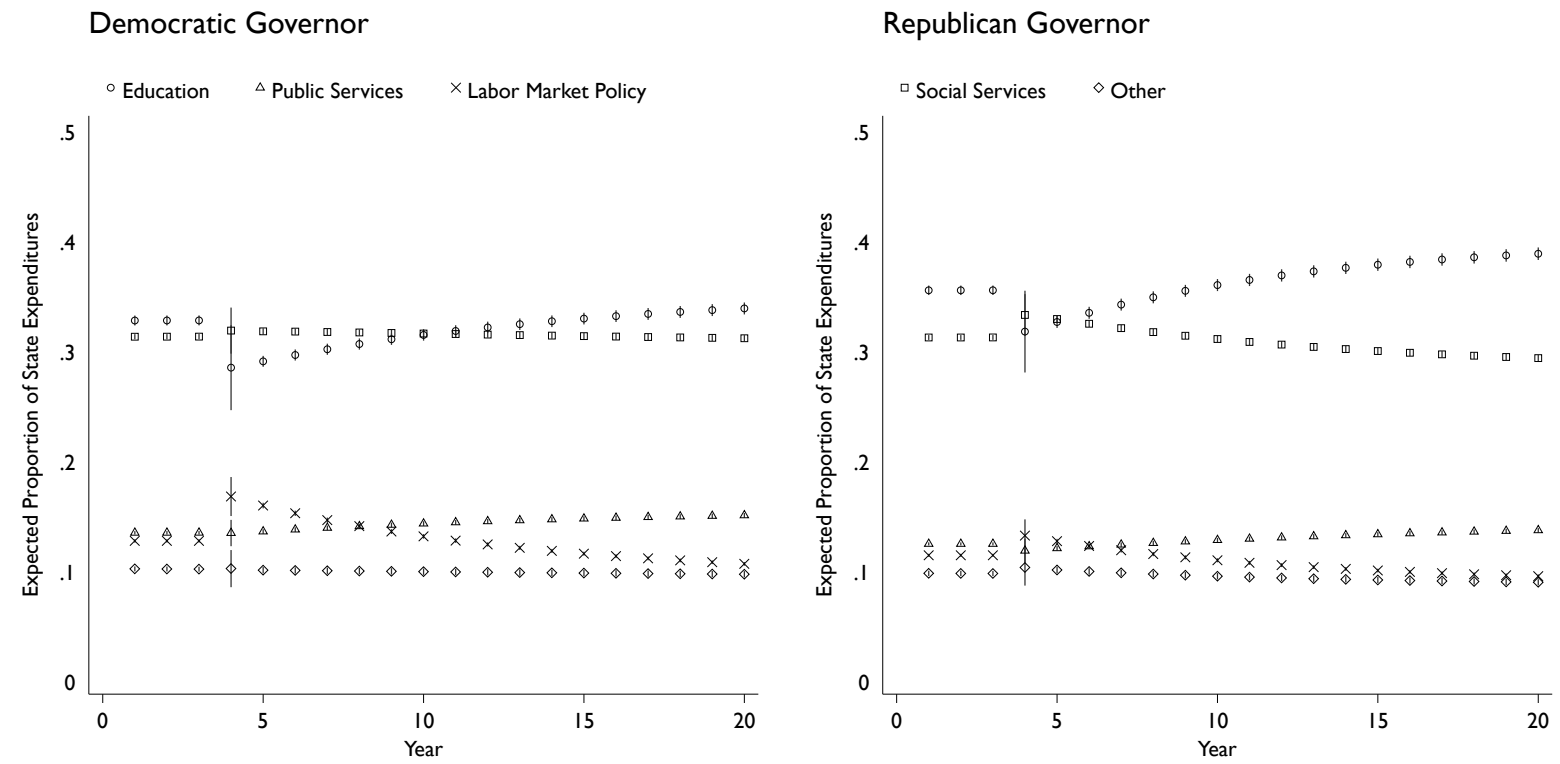

Figure 1: Change from baseline dynamic simulation of a 1 standard deviation decrease to average personal income. (Starting proportions are set to the sample means under a democratic and republican governor for the left and right plots, respectively.)

The graphs in Figure 1 allow us to draw a number of substantive conclusions. First, comparing the budgetary starting points for the first three time periods in both graphs, we can see that when all variables are held constant at their means, politics matters. States with a Democratic governor spend slightly more on social services, while states with a Republican governor spend more on education. Differences across the remaining categories are fairly small. When we observe the effects of a decrease in personal income at $t=4$, there are some similarities and some differences in how budgets change based on the party of the state governor. In both cases, there are substantial drops in the proportion of the budget spent on education and short-run increases in the share for labor market policy. The drop in education is larger for states controlled by a Democratic governor than a Republican one, and in the long run, Republican governors substantially increase the proportion 
of the state budget spent on education. In the short-run, the budgetary increase for labor market policy is greater under a Democratic governor than a Republican. In fact, in response to a decrease in average personal income, budgets under a Republican governor do not fluctuate nearly as much as under a Democrat governor.

Looking at unemployment, we present the predictions from a change in baseline dynamic simulation for a one standard deviation increase in unemployment in Figure 2. As before, we examine these effects for both a state with a Democratic (left plot) and Republican (right plot) governor. Unlike in Figure 1, the responses are largely the same across both types of party. In response to an increase in unemployment, both Democratic and Republican governors increase the proportion of the budget going to education, at the cost of social services, public services, and other parts of the budget. Perhaps surprisingly, labor market policy rises only slightly in response to an increase in unemployment.
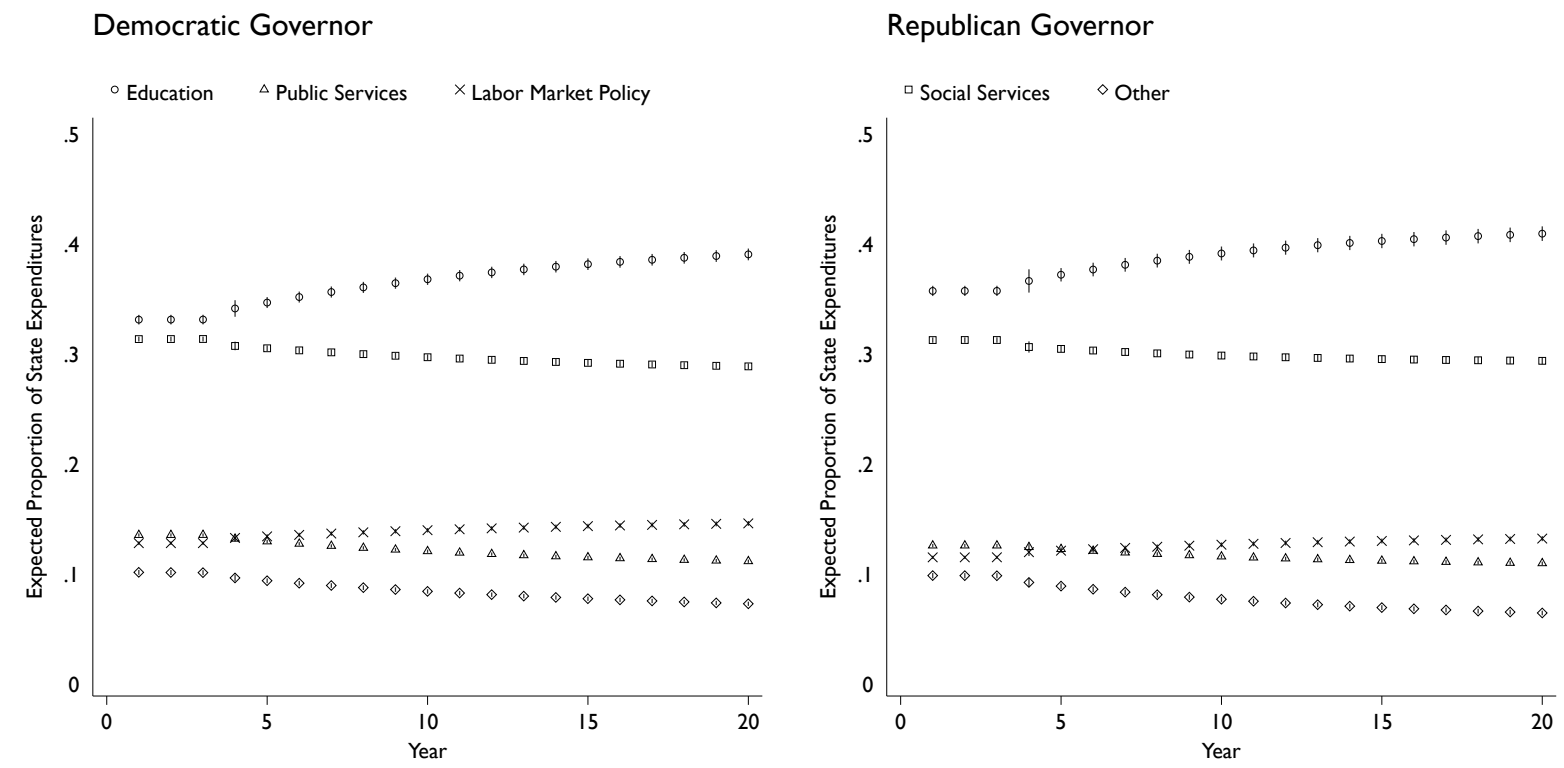

Figure 2: Change from baseline dynamic simulation of a 1 standard deviation increase in unemployment

Turning to the spatial effects, we present in Figure 3, the predictions from a change in baseline dynamic simulation for a one standard deviation increase in unemployment in other states, holding 
all else constant. Here we see much less dramatic budgetary reactions. In both graphs of Figure 3, we see increases in budgets on education and cuts in social services, and surprisingly, the cuts to social services are larger in the Democratic state. In both cases, we also see relative cuts to proportions on the other category and fairly slight cuts to spending on labor market policy and public services. Note too the contrast in the timing of the effects on the budget between internal shocks (Figures 1 and 2) and spatial shocks (Figure 3); spatial shocks tend to have immediate effects, while internal shocks tend to affect the budget much more, but only after a longer period of time.
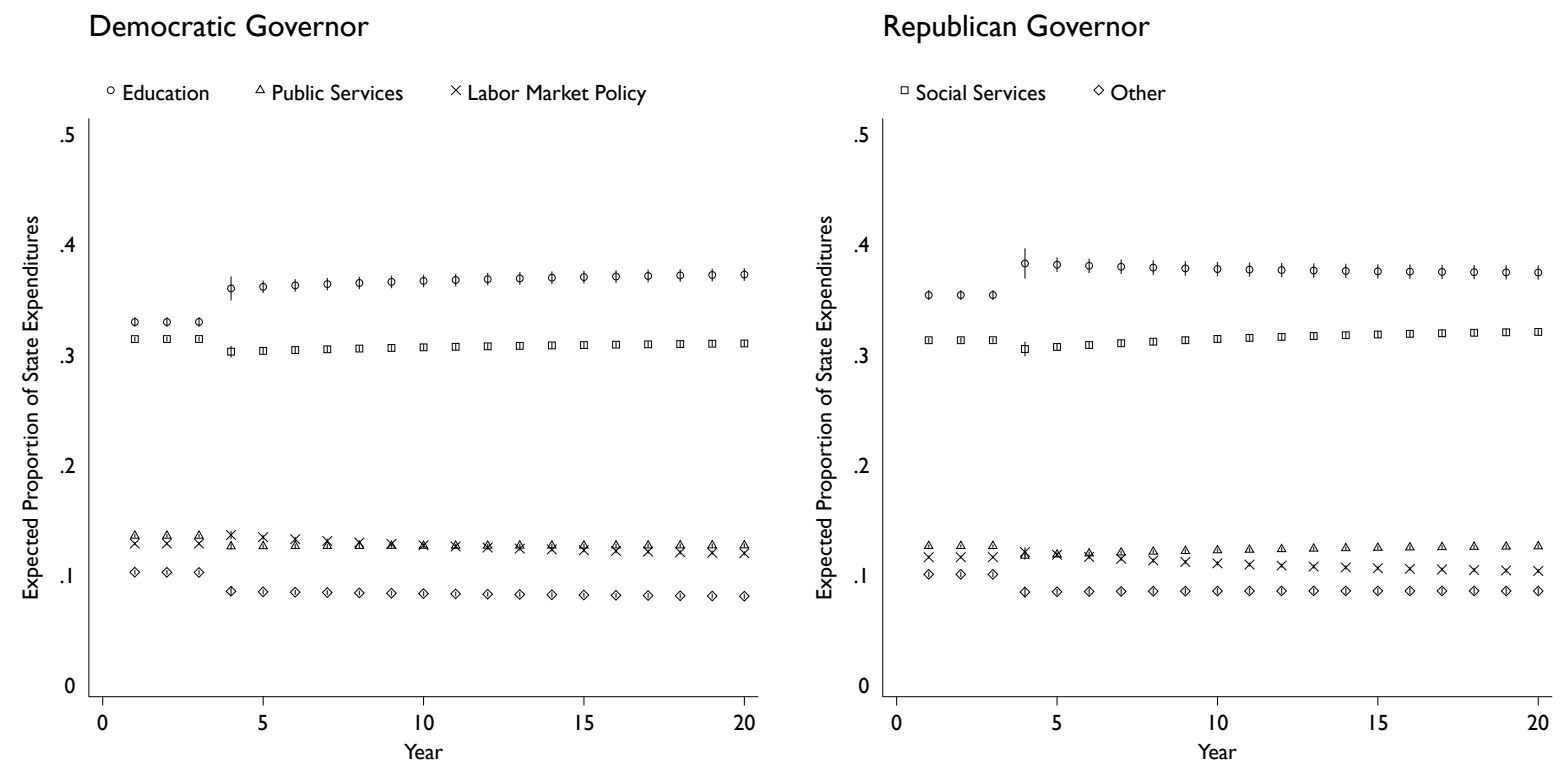

Figure 3: Change from baseline dynamic simulation of a 1 standard deviation increase in other states' unemployment

Change from baseline dynamic simulations like Figures 1 through 3 are helpful for understanding model inferences about the overall trajectories of different parts of a composition over both the short- and long-runs due to a change in the value of a particular independent variable. They represent substantial advancements over previous techniques used to visualize the estimated relationships from models of compositional dependent variables-such as simplex plots-that were limited in the number of dimensions they could present and quite difficult to interpret. However, 
even dynamic plots can be less than ideal for assessing three simple questions. First, is a particular change statistically significant in the short-run and/or the long-run? Second, is the predicted level of any pair of dependent variable categories overlapping in the short- and long-run? And third, does the relative ordering of the categories change; for example, does a category that was the largest proportion of the budget now become the second largest?

For a cleaner summary of the substantive implications of the results from the change in baseline simulations, we turn to an adaptation of the slope plot (Tufte 1983). In this type of figure, we display expected values for the start of a particular scenario (i.e., the "means" or baseline), the contemporaneous time period in which the simulated shock occurs, and then the long-run level of each category, each with associated confidence intervals. Figure 4 is an example of such a plot for the same income scenario depicted in Figure 1. As with the other figures, estimates for a scenario with a Democratic governor are shown in the left plot and for a Republican in the right. In each plot, the leftmost prediction, labeled "Means," is the expected proportion of each category when all of the independent variables are set to their sample means. The middle prediction in Figure 4, labeled "Short-Run," is the expected proportion of each category during the time period in which the one standard deviation decrease in average personal income occurred. The right-most prediction is the long-run expected value for each category that is a new equilibrium level predicted by our model, and the vertical lines running through each prediction depict 95 percent confidence intervals.

Figure 4 allows us to more clearly grasp the estimated changes in trajectory of the expected value of each category of state budgets. Moreover, the slope plot allows us to see if the relative ordering of the categories has changed over time. Note that in Figure 4, the long-run expected values are different from those at time period 20 in Figure 1, because the trajectories in Figure 1 have not fully adjusted to their new equilibrium values. For example, at time period 20 in the right panel in Figure 1, the budgetary proportion for labor market policy is significantly higher than "Other." But in the right panel of Figure 4, the long-run proportions for these two categories converges, and they are not significantly different from each other. Overall, Figure 4 helps to show that the three smallest budgetary categories do not end up being very different between Republican 

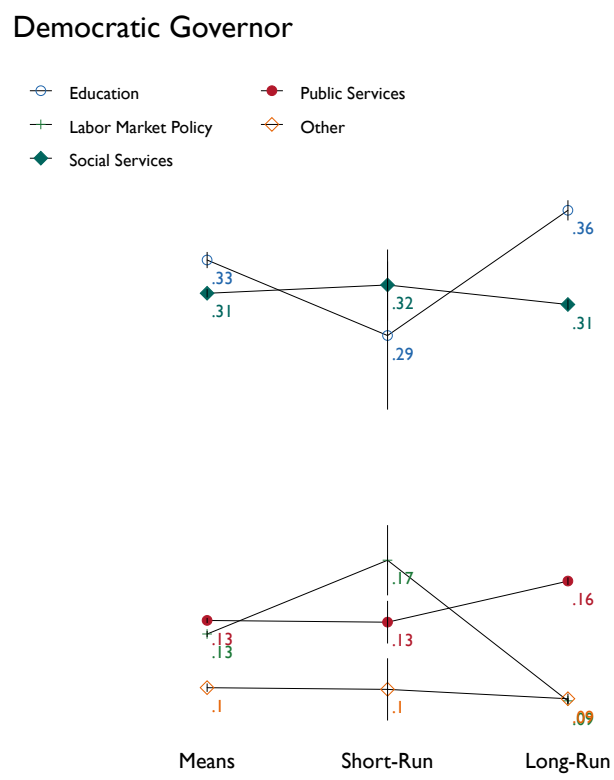

Republican Governor

$\because$ Education $\rightarrow$ Public Services

+ Labor Market Policy $\quad \diamond$ Other

- Social Services
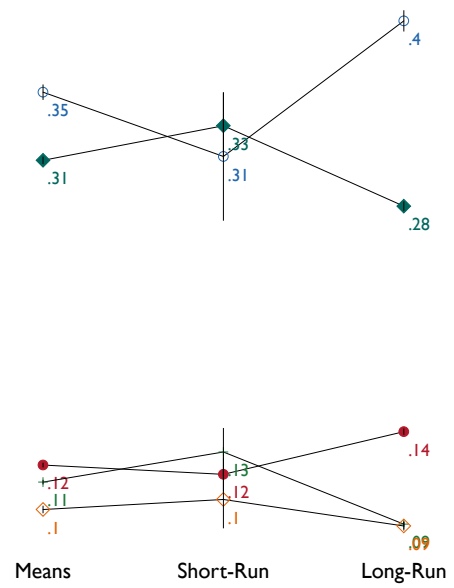

Figure 4: Slope plot for a change from baseline dynamic simulation for a 1 standard deviation decrease to average personal income

and Democratic governors, but education and social services are. In the long run, in response to a drop in average personal income, Republican governors spend about four percentage points more of their budget on education than Democratic ones, while Democratic governors spend about two percentage points more of their budget on social services than their Republican counterparts.

While both the change from baseline plots (e.g. Figure 1) and the slope plots (Figure 4) are useful depictions of the overall predicted trajectory of each category in the same dynamic simulation, it can be complicated to assess whether or not each of the expected short- and long-run changes is significantly different from zero in these types of plots. It is also difficult to discern whether or not these expected changes are different across categories or across the Democratic and Republican scenarios. In order to make these types of assessments, we advocate for the use of an "effects plot" that is similar to the types of coefficient plots that have become popular in recent years. In these plots, we depict both the expected short- and long-run changes to each category due to a change in baseline simulation. Figure 5 is an example of an effects plot for the same scenario of a one standard deviation decrease in average personal income, which we depicted in Figures 1 and 4. 
In both of the latter figures, it is difficult to determine whether the expected long-run effects are statistically significant for social services. In Figure 5, however, we can now tell that the that the expected 95 percent confidence intervals for the long-run decrease in social services are statistically significant for both parties, though Republican governors decrease social services by slightly over more over the long-run (and they increase it in the short-run). We can also identify that in the short-run, Democratic governors tend to allocate more of their budgets toward labor market policy than Republican governors (and both are statistically significantly different from zero). However, in the long run, states governed by a Democratic governor tend to decrease the proportion spent on labor market policy_even more so than Republicans-in response to a decrease in average personal income. This figure also makes it clear that, as is often the case with budgeting models, the short-run effects of a particular change tend to be quite modest and not statistically significant, while the long-run effects tend to be quite substantial.

This methodological illustration shows that our suggested strategies for extending the analysis of compositional dependent variables to time series cross sectional data work well. Although these models produce a large number of parameters, the estimated relationships from them can be easily understood through graphical depictions of post-estimation simulations.

\section{Modeling Spatially Lagged Dependent Variables}

So far, we have shown the utility of compositional time series models with spatially-lagged independent variables (spatial-X or SLX models). These specifications test the theoretical proposition that unemployment and personal income in spatially-proximate states are likely to have spillover effects on the composition of budgets in other states. However, most models incorporating spatial effects employ a spatially lagged dependent variable (commonly referred to as a spatial-autoregressive model, or SAR). Such models reflect a different type of theoretical proposition where the values of the dependent variable in one state effect the values of the dependent variable in others through diffusion or contagion processes. Using the same example as before, 


\section{Democratic Governor}

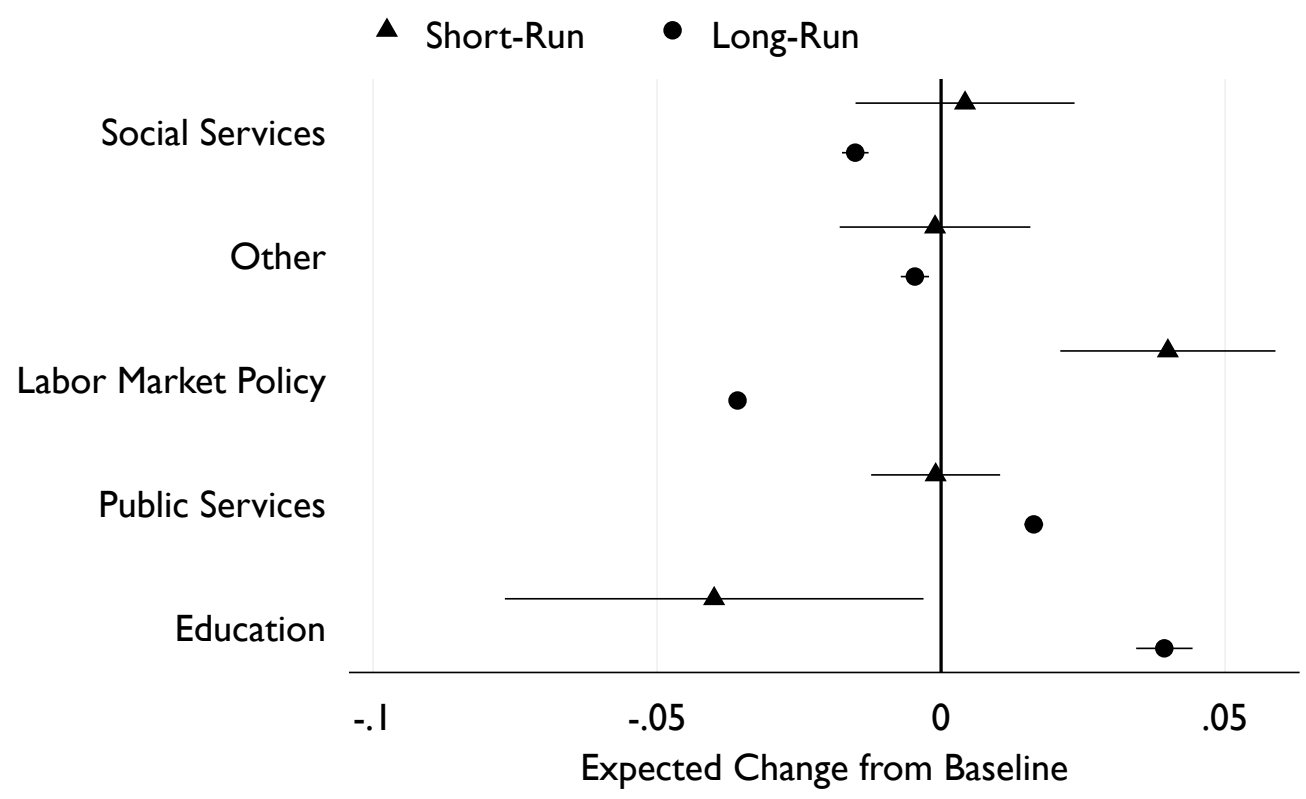

Republican Governor

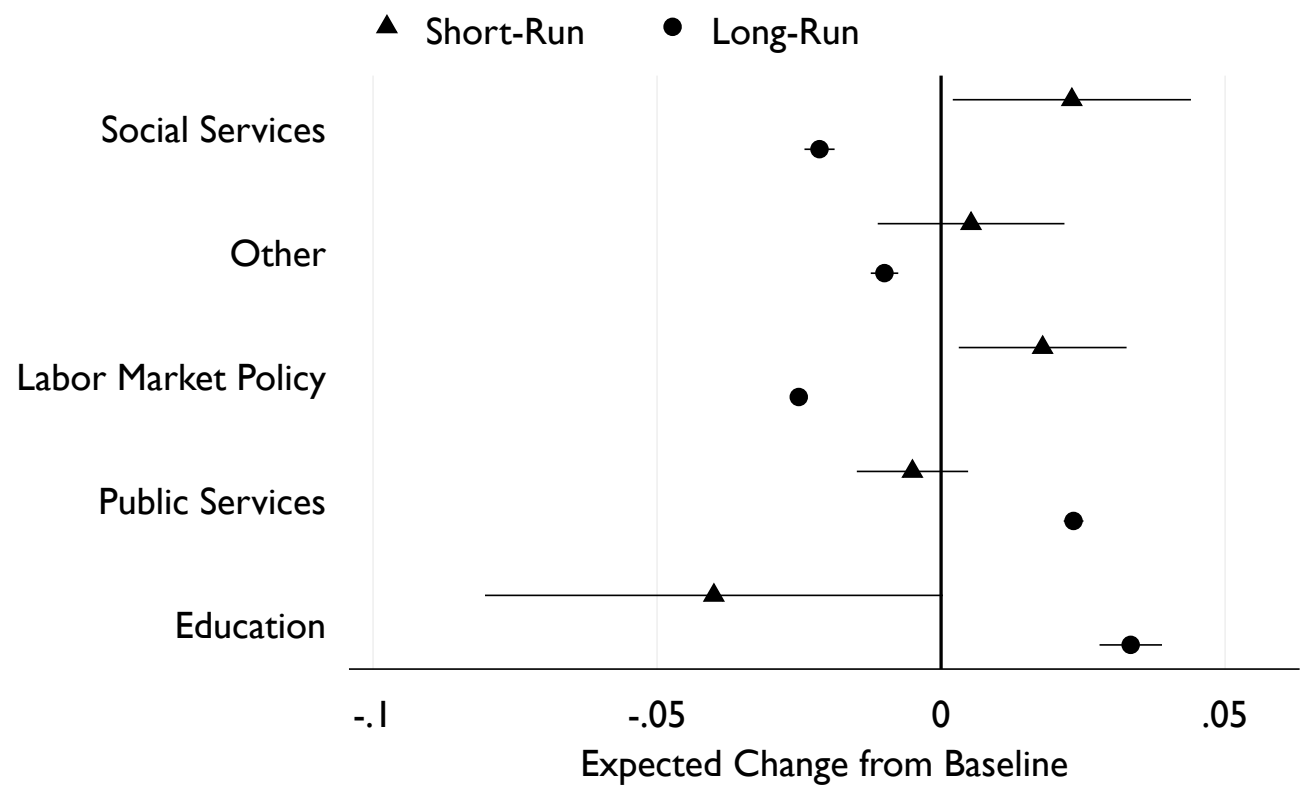

Figure 5: Effect plot for a change from baseline dynamic simulation for a 1 standard deviation decrease to average personal income 
we now specify our model as the following to allow for spatial relationships across values of the dependent variable:

$$
\Delta s_{i c t}=\beta_{0 c}+\lambda_{c} \mathbf{W} \Delta s_{j c t}+\left(1+d_{i t} \zeta_{c}\right)\left(\Delta x_{i t} \beta_{c}\right)+\varepsilon_{i c t}
$$

Thus, we now have a spatial autoregressive, or SAR model. We take the first differences of the dependent variable and the two independent variables-unemployment and personal income per capita - and we interact the latter two variables with the partisanship of the governor. ${ }^{16}$ While we assume that $\varepsilon_{i t c}$ is i.i.d., we estimate Equation 10 using generalized spatial two-stage least squares (Drukker, Prucha and Raciborski 2013) that allows us to account for potential heteroskedasticity. ${ }^{17}$

The results of the SAR models are shown in Table 1. The parameter of the spatial lag of the change in logged ratio compositions, $\lambda$, is statistically significant across all four models, indicating that spatial dependence is present in the data. However, the parameter of the spatial lag of the error term, $\rho$, is not statistically significant at conventional levels. This suggests that spatially correlated disturbances do not seem to be an issue in our models.

\section{Exploring the Substantive Implications of the Results}

Interpretation of the SAR results in Table 1 is not straightforward, since the coefficients are simultaneously determined with the SAR parameter, $\lambda$. As is common with applied spatial econometrics, we use substantively meaningful counterfactual scenarios in order to better understand our results (Ward and Gleditsch 2008). We use two approaches to explore the substantive implications of Table 1. First, we explore how movements in the composition of a given state's budget affect

\footnotetext{
${ }^{16}$ In future work, we plan on developing compositional models that include both spatial and temporal lags of the dependent variable.

${ }^{17}$ The models were estimated with Stata using the spreg program (Drukker, Prucha and Raciborski 2013). Note that unlike the SLX results, we could not account for contemporaneous correlation of errors across the four estimated models. In the future, we hope to incorporate this into compositional SAR models.
} 
Table 1: Compositional SAR Results

\begin{tabular}{|c|c|c|c|c|}
\hline & $\Delta \frac{\text { Education }}{\Delta \text { SocialServices }}$ & $\Delta \frac{\text { PublicServices }}{\text { SocialServices }}$ & $\bar{\Delta} \frac{\text { LaborMarketPol. }}{\text { SocialServices }}$ & $\overline{\Delta \Delta_{\text {Social Services }}}$ \\
\hline$\Delta$ Unemployment $_{t}$ & $\begin{array}{c}0.0085 \\
(0.0088)\end{array}$ & $\begin{array}{l}-0.0023 \\
(0.0051)\end{array}$ & $\begin{array}{c}0.0220^{* * *} \\
(0.0070)\end{array}$ & $\begin{array}{l}-0.0132 \\
(0.0081)\end{array}$ \\
\hline$\Delta$ Personal Income $_{t}$ & $\begin{array}{c}0.0016 \\
(0.0056)\end{array}$ & $\begin{array}{l}0.0121^{*} \\
(0.0065)\end{array}$ & $\begin{array}{l}-0.0001 \\
(0.0076)\end{array}$ & $\begin{array}{l}0.0138^{* *} \\
(0.0064)\end{array}$ \\
\hline $\begin{array}{l}\text { Democratic Governor }_{t} \\
\Delta \text { Unemployment }_{t}\end{array}$ & $\begin{array}{c}0.0011 \\
(0.0104)\end{array}$ & $\begin{array}{l}-0.0016 \\
(0.0064)\end{array}$ & $\begin{array}{c}0.0008 \\
(0.0082)\end{array}$ & $\begin{array}{c}0.0086 \\
(0.0097)\end{array}$ \\
\hline $\begin{array}{l}\text { Democratic Governor }_{t} \cdot \\
\Delta \text { Personal Income }_{t}\end{array}$ & $\begin{array}{l}-0.0069 \\
(0.0099)\end{array}$ & $\begin{array}{l}-0.0075 \\
(0.0093)\end{array}$ & $\begin{array}{l}-0.0191^{*} \\
(0.0110)\end{array}$ & $\begin{array}{c}0.0026 \\
(0.0098)\end{array}$ \\
\hline Democratic Governor $_{t}$ & $\begin{array}{c}0.0037 \\
(0.0091)\end{array}$ & $\begin{array}{l}-0.0011 \\
(0.0077)\end{array}$ & $\begin{array}{c}0.0060 \\
(0.0096)\end{array}$ & $\begin{array}{l}-0.0019 \\
(0.0096)\end{array}$ \\
\hline Constant & $\begin{array}{c}0.0012 \\
(0.0059)\end{array}$ & $\begin{array}{c}-0.0157^{* * *} \\
(0.0060)\end{array}$ & $\begin{array}{l}-0.0013 \\
(0.0071)\end{array}$ & $\begin{array}{c}-0.0233^{* * *} \\
(0.0071)\end{array}$ \\
\hline$\lambda$ & $\begin{array}{c}0.1534^{* * *} \\
(0.0159)\end{array}$ & $\begin{array}{c}0.1715^{* * *} \\
(0.0345)\end{array}$ & $\begin{array}{c}0.1751^{* * *} \\
(0.0134)\end{array}$ & $\begin{array}{c}0.1612^{* * *} \\
(0.0179)\end{array}$ \\
\hline$N$ & 1536 & 1536 & 1536 & 1536 \\
\hline States & 48 & 48 & 48 & 48 \\
\hline
\end{tabular}

Note: Generalized spatial two-stage least squares with standard errors in parentheses. Two-tail tests. ${ }^{*} p<0.10,{ }^{* *}$ $p<0.05,{ }^{* * *} p<0.01$ 
the budget compositions of spatially-proximate states. Second, we explore equilibrium effects of changes in a particular covariate, taking into account the spatial lag.

As shown in Table 1, the parameter on the spatial lag is positive and significant for all four equations. This suggests that, as expected, movements in the budget of one state tend to be associated with similar movements in their spatially-proximate neighbors. What would happen to the budgets of other $j$ states, given a budgetary change in state $i ?^{18}$ For instance consider the following scenario. Relative to the previous year, in 2000 Ohio reduced the proportion of expenditures allocated towards education by about 0.5 percentage points. That same year, New Hampshire experienced a large change in education, increasing the share of expenditures by about 11 percentage points. What would the effect be on other states if Ohio would have experienced the same increase as New Hampshire?

Since the dependent variable is compositional, we assume that the 11 percentage point increase to education comes at the expense of all other categories evenly (that is, 2.75 percentage points). ${ }^{19}$ Given that the dependent variable is a logged ratio between two expenditures, the change in Ohio's budget needs to be expressed in logged ratio form as well. ${ }^{20}$ We then multiply the spatial weights matrix by a vector of zeros for every state-year except for Ohio in 2000 , which experiences the counterfactual change. This is done for each of the four logged-ratios. The resulting vectors are then multiplied by the estimated $\lambda$ for each model, respectively. These vectors show the estimated change in logged-ratio compositions, for each state $j$, given the increase in education expenditures in state $i$ (Ohio). For instance, the 25 largest predicted changes in the logged ratio of education to social services is shown in the middle column in Table 2. Last, given each predicted change in logged ratio, and the actual values for spending in 1999, we can back out the predicted change in

\footnotetext{
${ }^{18}$ Note that this scenario assumes that budgetary changes are not due to the systematic part of the model (Ward and Gleditsch 2008); instead, we are examining the effects that budgetary movements in a given state $i$ have on the budgets of their $j$ neighbors.

${ }^{19}$ Assuming a uniform decrease in the other categories is ideal since it comes closest to the "ratio-preserving" counterfactual (Adolph 2013; Philips, Rutherford and Whitten 2016a).

${ }^{20}$ For instance, the counterfactual change from 1999 to $2000 \mathrm{in} \ln \left(\frac{\text { Education }}{\text { Social Services }}\right)$ is: $\ln \left(\frac{\text { Education }_{1999}+0.11}{\text { Social Services }_{1999}-0.0275}\right)-$ $\ln \left(\frac{\text { Education }_{1999}}{\text { Social Services }_{1999}}\right)$.
} 
each of the budget categories using the untransformation formulae given in Equations 8 and 9. The predicted percentage point changes are shown in the right-hand column in Table 2.

Table 2: 25 Largest Predicted Changes in Education in Response to an 11 Percentage Point Increase in Ohio's Education Expenditures

\begin{tabular}{ccc}
\hline \hline Name & Predicted $\Delta \ln \left(\frac{\text { Education }}{\text { Social Services }}\right)$ & Predicted Percentage Change in Education \\
VT & .0133009 & .3835261 \\
DE & .014509 & .3831297 \\
VA & .0137377 & .3789872 \\
IN & .0126404 & .3614187 \\
NC & .0126689 & .356549 \\
MD & .0146981 & .3527939 \\
WV & .0134851 & .3435671 \\
NJ & .0141675 & .3380179 \\
KY & .0133036 & .3377914 \\
MA & .0171505 & .3370076 \\
RI & .0161889 & .3325716 \\
TN & .0129066 & .3247052 \\
GA & .0113302 & .320676 \\
AR & .0110825 & .3085881 \\
AL & .0115183 & .3084749 \\
KS & .0102424 & .3030658 \\
CT & .0153873 & .2997711 \\
MO & .0114182 & .2990395 \\
IA & .0106624 & .2908617 \\
SC & .0118244 & .290671 \\
MI & .0101265 & .2904415 \\
MS & .0112275 & .286296 \\
OK & .0099582 & .2828717 \\
PA & .0133325 & .2820015 \\
WI & .0100436 & Notes: \\
\hline \hline & & \\
& & \\
\hline
\end{tabular}

To better visualize these predicted changes, we show both the predicted change in logged ratio (top) and the predicted change in education expenditures (bottom) in Figure 6. As is the case with a logit model, the predicted log-ratio changes are linear, but the predicted percentage changes are not. The size of the predicted percentage changes depends on both the starting value of predicted percentage and the size of the predicted log-ratio change. 


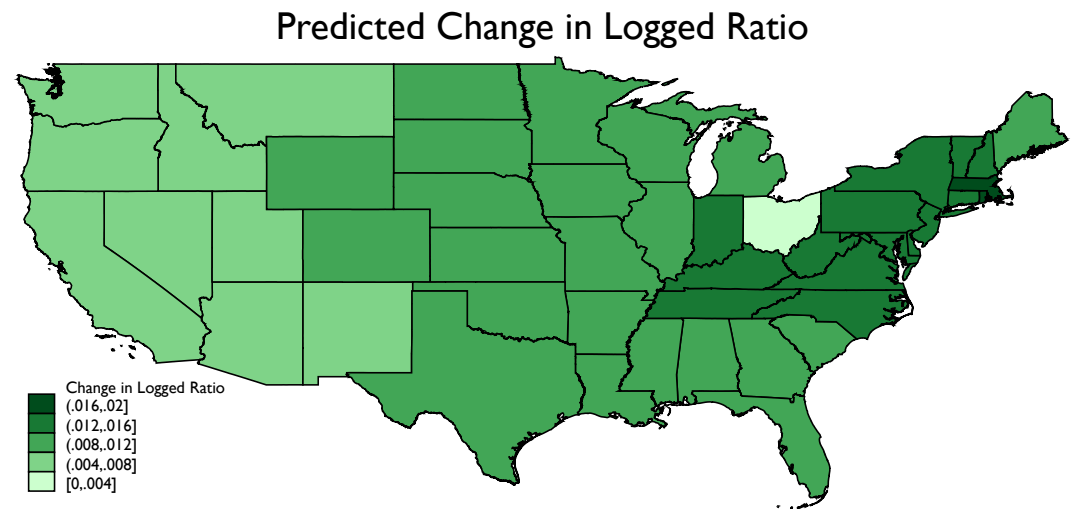

Predicted Change in Education Expenditures

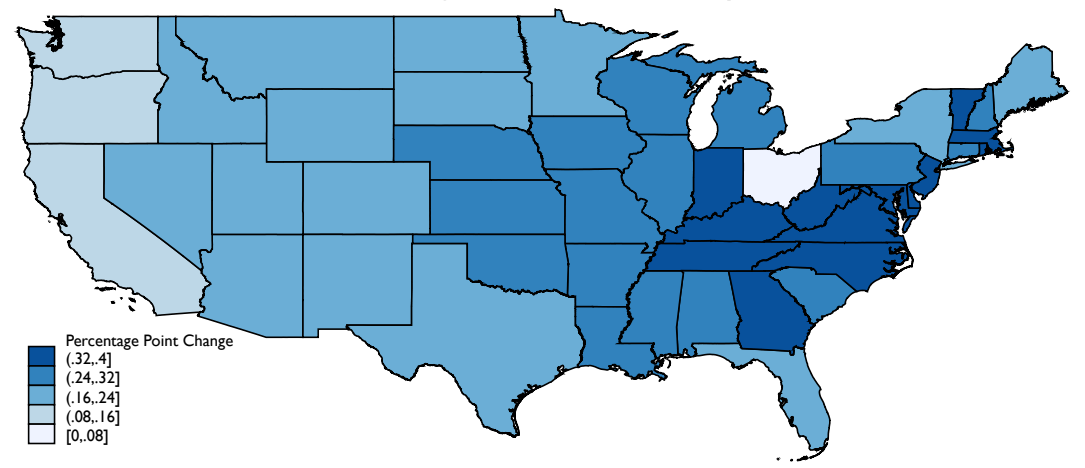

Figure 6: Predicted Effect of an 11 Percentage Point Increase in Ohio's Education Expenditures 


\section{SAR Reduced Form Predictions}

As a second approach to visualizing the substantive meaning of our results in Table 1, we use reduced form predictions of the impact of simultaneously increasing the personal income in all states by $\$ 1000$ per capita in the year 2000. We hold the political variable, Democratic governor, constant and calculate reduced form predictions using Table 1 and the actual values of personal income in the year 2000. We then calculate reduced form predictions for the same year but add $\$ 1000$ to each state's personal income. Since these predictions are still in compositional form, we un-transform them using Equations 8 and 9 and then calculate the difference between the predictions given the counterfactual change and the predictions without that change.

In Figure 7, we present the results for two of the five budgetary categories. As shown in Figure $7 \mathrm{a}$, as a result of a uniform increase of $\$ 1000$ in personal income across all the states in 2000 , all states except for Oregon and Washington spend less on social services, as a percentage of the total budget. Massachusetts is the clear outlier, reducing expenditures by more than .4 percent of the total budget. Most other states reduce social services by between and 0.1 and 0.3 percentage points, with only a few states (Alabama, California, Georgia, Indiana, North Carolina) decreasing spending by less than 0.1 percentage points. Averaging across all states or calculating the average total impact (ATI) (Drukker, Prucha and Raciborski 2013), results in an average decrease of just under one fifth of one percentage point.

Similar to social services, as shown in Figure $7 \mathrm{~b}$, all states also spend relatively less, as a percent of the total budget, on education as a result of a counterfactual increase in personal income. The largest relative decreases are in Vermont and Virginia. The smallest decreases appear to be clustered on the West coast and in the Northeast. The ATI for education is -0.28 , meaning that after taking into account spatial effects, the average US state allocates just under one third of a percentage point less to its education budget, given an increase of $\$ 1000$ to personal income in states. $^{21}$

\footnotetext{
${ }^{21}$ The ATI for the other three categories were $-0.20,0.26$, and 0.41 , for labor market, public service, and other, respectively.
} 


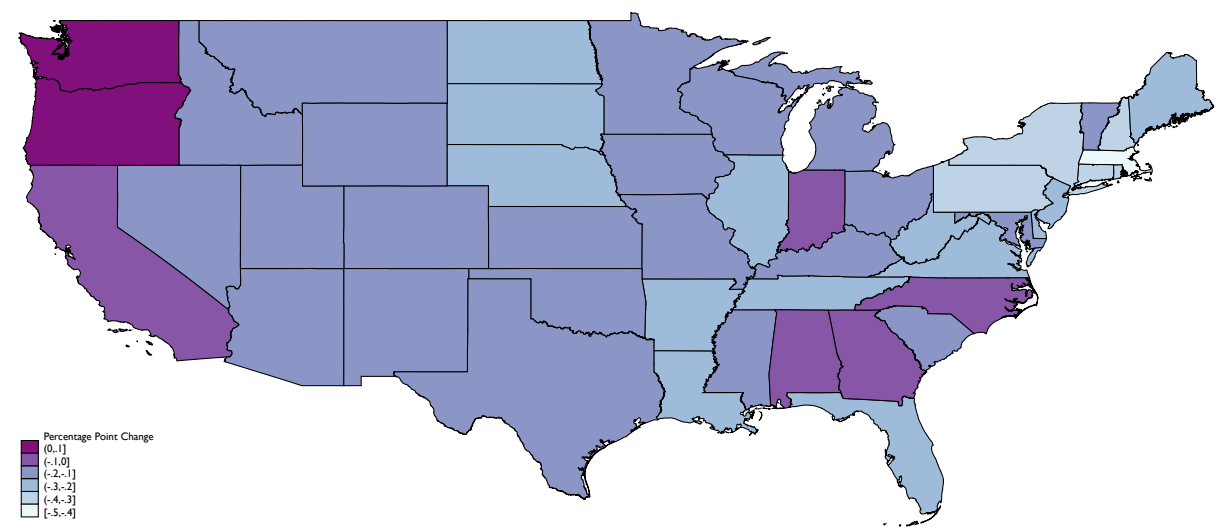

(a) Change in Social Services (as \% of Budget)

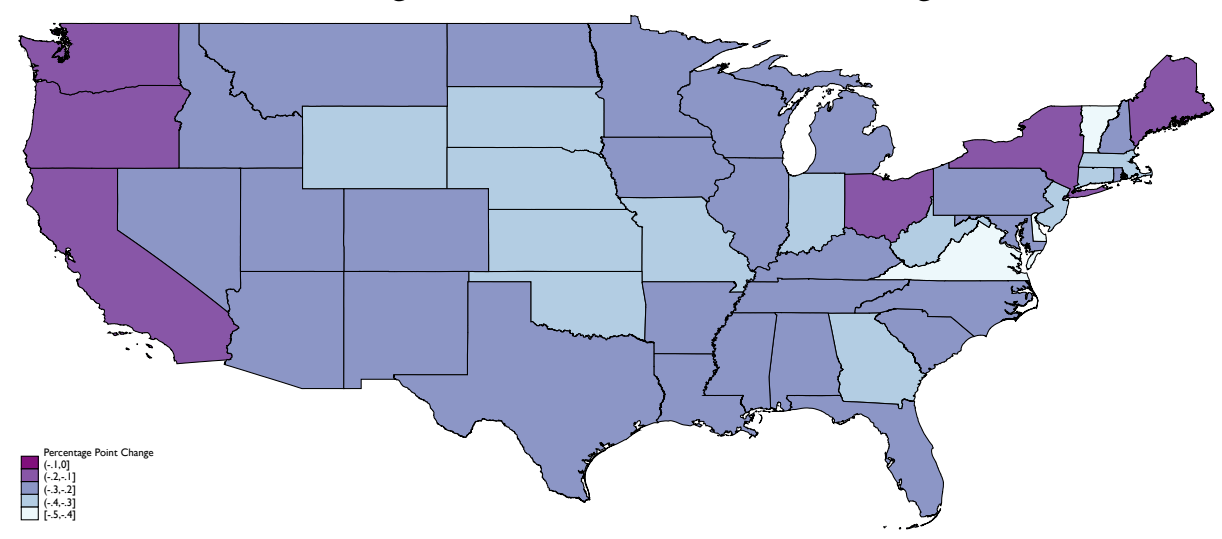

(b) Change in Education (as \% of Budget)

Figure 7: The Effect of a $\$ 1000$ Increase in Personal Income in All States in 2000 


\section{Conclusions and Future Directions}

Many important theories in political science and public policy involve compositional dependent variables that vary in interesting ways across time and space. In many cases, however, researchers oversimplify trade-offs to compare just two categories, and they ignore the importance of the effects of time and space. This is especially the case in budgeting, where research has generally focused on trends in one category of spending (i.e., punctuated equilibrium) or the trade-off between two categories (i.e., guns vs. butter). In this paper, we have built upon existing approaches, emphasizing dynamic changes to incorporate spatial effects and interactions with contextual variables in time series cross sectional settings. Through the use of graphical depictions of dynamic simulations, we have shown how our proposed strategy produces a rich set of inferences that can illustrate short- and long-term substantive effects.

In the context of U.S. state expenditures, we have been able to demonstrate how spending tradeoffs vary across different governing parties, while also accounting for spillover effects from conditions in other states. While exploring these differences, our approach illustrates how economic shifts, such as a change in income or unemployment can affect relative spending across multiple budgetary categories. Moreover, we find that they also receive different shares of funding from Democrats and Republicans, and that partisanship conditions the effects of economic changes. By incorporating potential spatial effects, we show that not only do surrounding economic conditions affect state budget allocations, but partisanship conditions these effects as well. To assist researchers in the interpretation of their results, we have also adapted a variety of graphical tools for dynamic compositional models.

In future work, there are a number of ways in which our models can be expanded. First, the temporal dynamics of our approach may be extended through vector error correction (VEC) models that allow us to consider further issues of cointegration. We also are interested in exploring alternative specifications of the spatial weights matrix in order to better model spatial contagion and diffusion from one spatial unit to another. Finally, while we focus this application on the 
case of state-level budgets, we intend to show the generalizability of our approach to many other political phenomena across multiple countries and policy areas, including political campaigns, issue attention, and income inequality. By advancing our approach and making it accessible to quantitative researchers, we have shown that one can study the space and time characteristics of compositional variables in a broad range of contexts to more closely mirror observed realities. 


\section{Appendix-Table of Numerical Results}


Table 3: Results for the Budget Composition

\begin{tabular}{|c|c|c|c|c|}
\hline & $\begin{array}{l}\frac{\text { Education }}{\text { SocialServices }} \\
\text { (1) }\end{array}$ & $\begin{array}{l}\text { PublicServices } \\
\text { SocialServices } \\
\text { (2) }\end{array}$ & $\begin{array}{l}\text { LaborMarketPol. } \\
\text { SocialServices } \\
\text { (3) }\end{array}$ & $\begin{array}{c}\text { Other } \\
\text { SocialServices } \\
\text { (4) }\end{array}$ \\
\hline Lagged Dependent Variable & $\begin{array}{c}-0.106^{* * *} \\
(0.014)\end{array}$ & $\begin{array}{c}-0.087^{* * *} \\
(0.011)\end{array}$ & $\begin{array}{c}-0.102^{* * *} \\
(0.013)\end{array}$ & $\begin{array}{c}-0.060^{* * *} \\
(0.010)\end{array}$ \\
\hline Lagged Dep. Var $x$ & 0.014 & 0.012 & 0.017 & 0.012 \\
\hline Democratic Governor & $(0.017)$ & $(0.014)$ & $(0.017)$ & $(0.014)$ \\
\hline$\Delta$ Unemployment $_{t}$ & $\begin{array}{c}0.026^{* * *} \\
(0.008)\end{array}$ & $\begin{array}{c}0.002 \\
(0.005)\end{array}$ & $\begin{array}{c}0.028^{* * *} \\
(0.006)\end{array}$ & $\begin{array}{c}-0.023^{* * *} \\
(0.007)\end{array}$ \\
\hline Unemployment $_{t-1}$ & $\begin{array}{c}0.012^{* * *} \\
(0.004)\end{array}$ & $\begin{array}{c}-0.006^{* *} \\
(0.003)\end{array}$ & $\begin{array}{c}0.010^{* * *} \\
(0.004)\end{array}$ & $\begin{array}{c}-0.017^{* * *} \\
(0.004)\end{array}$ \\
\hline$\Delta \mathbf{W} \cdot$ Unemployment $_{t}$ & $\begin{array}{c}0.012^{* * *} \\
(0.002)\end{array}$ & $\begin{array}{l}-0.005^{* * *} \\
(0.001)\end{array}$ & $\begin{array}{c}0.007^{* * *} \\
(0.002)\end{array}$ & $\begin{array}{c}-0.017^{* * *} \\
(0.002)\end{array}$ \\
\hline $\mathbf{W} \cdot$ Unemployment $_{t-1}$ & $\begin{array}{c}0.000 \\
(0.001)\end{array}$ & $\begin{array}{l}-0.000 \\
(0.001)\end{array}$ & $\begin{array}{c}-0.002^{* * *} \\
(0.001)\end{array}$ & $\begin{array}{l}-0.001 \\
(0.001)\end{array}$ \\
\hline$\Delta$ Personal Income $_{t}$ & $\begin{array}{c}0.022^{* * *} \\
(0.008)\end{array}$ & $\begin{array}{l}0.009^{*} \\
(0.005)\end{array}$ & $\begin{array}{c}-0.024^{* * *} \\
(0.006)\end{array}$ & $\begin{array}{c}0.002 \\
(0.007)\end{array}$ \\
\hline Personal Income $_{t-1}$ & $\begin{array}{c}-0.003^{* * *} \\
(0.001)\end{array}$ & $\begin{array}{c}-0.003^{* * *} \\
(0.001)\end{array}$ & $\begin{array}{c}0.003^{* * *} \\
(0.001)\end{array}$ & $\begin{array}{c}0.000 \\
(0.001)\end{array}$ \\
\hline $\begin{array}{l}\Delta\left(\text { Democratic Governor }_{t} x\right. \\
\left.\text { Unemployment }_{t}\right)\end{array}$ & $\begin{array}{l}-0.000 \\
(0.007)\end{array}$ & $\begin{array}{l}-0.003 \\
(0.005)\end{array}$ & $\begin{array}{c}0.003 \\
(0.006)\end{array}$ & $\begin{array}{c}0.007 \\
(0.006)\end{array}$ \\
\hline $\begin{array}{l}\text { Democratic Governor }_{t-1} x \\
\text { Unemployment }_{t-1} \text { ) }\end{array}$ & $\begin{array}{c}0.003 \\
(0.006)\end{array}$ & $\begin{array}{c}0.001 \\
(0.004)\end{array}$ & $\begin{array}{c}0.003 \\
(0.005)\end{array}$ & $\begin{array}{c}0.006 \\
(0.005)\end{array}$ \\
\hline $\begin{array}{l}\Delta\left(\text { Democratic Governor }_{t} x\right. \\
\left.\mathbf{W} \cdot \text { Unemployment }_{t}\right)\end{array}$ & $\begin{array}{c}0.001 \\
(0.002)\end{array}$ & $\begin{array}{c}0.000 \\
(0.001)\end{array}$ & $\begin{array}{l}0.003^{* *} \\
(0.001)\end{array}$ & $\begin{array}{c}0.001 \\
(0.001)\end{array}$ \\
\hline $\begin{array}{l}\text { (Democratic Governor }_{t-1} x \\
\text { W.Unemployment } \\
t-1\end{array}$ & $\begin{array}{c}0.001 \\
(0.001)\end{array}$ & $\begin{array}{l}-0.000 \\
(0.001)\end{array}$ & $\begin{array}{c}0.001 \\
(0.001)\end{array}$ & $\begin{array}{l}-0.000 \\
(0.001)\end{array}$ \\
\hline $\begin{array}{l}\Delta\left(\text { Democratic Governor }_{t} x\right. \\
\left.\text { Personal Income }_{t}\right)\end{array}$ & $\begin{array}{c}0.002 \\
(0.002)\end{array}$ & $\begin{array}{c}0.001 \\
(0.001)\end{array}$ & $\begin{array}{l}0.003^{*} \\
(0.002)\end{array}$ & $\begin{array}{c}0.002 \\
(0.002)\end{array}$ \\
\hline $\begin{array}{l}\text { Democratic Governor }_{t-1} x \\
\text { Personal Income } \\
t-1\end{array}$ & $\begin{array}{c}0.002 \\
(0.002)\end{array}$ & $\begin{array}{c}0.001 \\
(0.001)\end{array}$ & $\begin{array}{c}0.001 \\
(0.001)\end{array}$ & $\begin{array}{l}-0.001 \\
(0.001)\end{array}$ \\
\hline$\Delta$ Democratic Governor $_{t}$ & $\begin{array}{l}-0.096 \\
(0.093)\end{array}$ & $\begin{array}{l}-0.033 \\
(0.059)\end{array}$ & $\begin{array}{c}-0.202^{* * *} \\
(0.070)\end{array}$ & $\begin{array}{l}-0.126 \\
(0.080)\end{array}$ \\
\hline Democratic Governor $_{t-1}$ & $\begin{array}{l}-0.114 \\
(0.071)\end{array}$ & $\begin{array}{l}-0.014 \\
(0.046)\end{array}$ & $\begin{array}{l}-0.036 \\
(0.059)\end{array}$ & $\begin{array}{c}0.006 \\
(0.062)\end{array}$ \\
\hline Constant & $\begin{array}{c}0.026 \\
(0.050)\end{array}$ & $\begin{array}{c}0.038 \\
(0.031)\end{array}$ & $\begin{array}{c}-0.187^{* * *} \\
(0.043)\end{array}$ & $\begin{array}{c}0.043 \\
(0.041)\end{array}$ \\
\hline$N$ & 1536 & 1536 & 1536 & 1536 \\
\hline States & 48 & 48 & 48 & 48 \\
\hline $\mathrm{R}-\mathrm{Sq}$. & 0.17 & 0.11 & 0.26 & 0.24 \\
\hline$\chi^{2}$ & $413.17^{* * *}$ & $187.17^{* * *}$ & $557.42^{* * *}$ & $502.03^{* * *}$ \\
\hline
\end{tabular}

Note: Regression with standard errors in parentheses. Two-tail tests. ${ }^{*} p<0.10,{ }^{* *} p<0.05,{ }^{* * *} p<0.01$ 


\section{References}

Adolph, Christopher. 2013. Bankers, Bureaucrats, and Central Bank Politics: The Myth of Neutrality. Cambridge University Press.

Aitchison, John. 1982. “The statistical analysis of compositional data.” Journal of the Royal Statistical Society. Series B (Methodological) 44(2):139-177.

Aitchison, John. 1983. "Principal component analysis of compositional data." Biometrika 70(1):57-65.

Aitchison, John. 1986. The statistical analysis of compositional data. Chapman \& Hall, Ltd.

Beck, Nathaniel, Kristian Skrede Gleditsch and Kyle Beardsley. 2006. "Space is more than geography: Using spatial econometrics in the study of political economy." International Studies Quarterly 50(1):27-44.

Breunig, Christian and Marius Busemeyer. 2012. "Fiscal austerity and the trade-off between public investment and social spending." Journal of European Public Policy 19:921-938.

Clark, Tom S and Drew A Linzer. 2015. "Should I use fixed or random effects?" Political Science Research and Methods 3(02):399-408.

Darmofal, David. 2015. Spatial Analysis for the Social Sciences. Cambridge University Press.

Drukker, David M, Ingmar R Prucha and Rafal Raciborski. 2013. "Maximum likelihood and generalized spatial two-stage least-squares estimators for a spatial-autoregressive model with spatial-autoregressive disturbances.” The Stata journal 13(2):221-241.

Franzese, Robert J and Jude C Hays. 2007. "Spatial econometric models of cross-sectional interdependence in political science panel and time-series-cross-section data." Political Analysis 15(2):140-164. 
Halleck Vega, Solmaria and J Paul Elhorst. 2015. “The SLX Model.” Journal of Regional Science

Jackson, John E. 2002. “A seemingly unrelated regression model for analyzing multiparty elections." Political Analysis 10(1):49-65.

Katz, Jonathan N and Gary King. 1999. “A statistical model for multiparty electoral data.” American Political Science Review pp. 15-32.

Klarner, Carl. 2013a. "State Economic Data.” http://hdl.handle.net/1902.1/20404 IQSS Dataverse Network.

Klarner, Carl. 2013b. "State Partisan Balance Data, 1937-2011." http://hdl.handle.net/1902.1/20403 IQSS Dataverse Network.

Mikhailov, Nikolai, Richard G Niemi and David L Weimer. 2002. "Application of Theil group logit methods to district-level vote shares: tests of prospective and retrospective voting in the 1991, 1993, and 1997 Polish elections.” Electoral Studies 21(4):631-648.

Neumayer, Eric and Thomas Plümper. 2012. "Conditional spatial policy dependence theory and model specification.” Comparative Political Studies 45(7):819-849.

Philips, Andrew, Amanda Rutherford and Guy D. Whitten. 2016a. "Dynamic pie: A strategy for modeling trade-offs in compositional variables over time." American Journal of Political Science 60(1):268-283.

Philips, Andrew Q, Amanda Rutherford and Guy D Whitten. 2015. "The dynamic battle for pieces of pie-Modeling party support in multi-party nations.” Electoral Studies 39:264-274.

Philips, Andrew Q, Amanda Rutherford and Guy D. Whitten. 2016b. "Dynsimpie: A program to examine dynamic compositional dependent variables.” Stata Journal 16(3):662-677. 
Plümper, Thomas and Vera E Troeger. 2007. "Efficient estimation of time-invariant and rarely changing variables in finite sample panel analyses with unit fixed effects." Political Analysis 15(2):124-139.

Tomz, Michael, Jason Wittenberg and Gary King. 2003. "Clarify: Software for Interpreting and Presenting Statistical Results.” Journal of Statistics Software 8(1):1-30.

Tomz, Michael, Joshua Tucker and Jason Wittenberg. 2002. "An Easy and Accurate Regression Model for Multiparty Electoral Data." Political Analysis 10:66-83.

Tufte, Edward R. 1983. The visual display of quantitative information. Vol. 2 Graphics press Cheshire, CT.

Wang, Huiwen, Qiang Liu, Henry MK Mok, Linghui Fu and Wai Man Tse. 2007. "A hyperspherical transformation forecasting model for compositional data." European journal of operational research 179(2):459-468.

Ward, Michael D and Kristian Skrede Gleditsch. 2008. Spatial regression models. Vol. 155 of Quantitative Applications in the Social Sciences Sage Publications.

Williams, Laron K and Guy D Whitten. 2011. "Dynamic simulations of autoregressive relationships.” Stata Journal 11(4):577-588.

Williams, Laron K and Guy D Whitten. 2012. "But wait, theres more! Maximizing substantive inferences from TSCS models.” The Journal of Politics 74(03):685-693. 